\title{
Buckling Analysis of Cracked Plates Using Peridynamics
}

\author{
Jeeyeon $\mathrm{Heo}^{1}$, Zhenghao Yang ${ }^{1}$, Wenxuan $\mathrm{Xia}^{1}$, Selda Oterkus ${ }^{1}$ and Erkan Oterkus ${ }^{1 *}$ \\ ${ }^{1}$ PeriDynamics Research Centre, Department of Naval Architecture, Ocean and Marine Engineering, \\ University of Strathclyde, 100 Montrose Street Glasgow G4 OLZ, United Kingdom
}

Abstract: In this study, buckling analysis of cracked plates is performed by using peridynamics. A peridynamic Mindlin plate formulation is used and the numerical implementation is done using commercial finite element software, ANSYS. Critical buckling load is obtained by utilizing ANSYS Eigenvalue Buckling Analysis feature. Peridynamic results are compared against numerical and experimental results and a good agreement is obtained between different approaches. After verifying the formulation, it is utilised to investigate the effect of crack length, crack orientation and plate thickness on the critical buckling load values for a centrally and side-edge cracked plates subjected to clamped-free-clamped-free (CFCF) boundary conditions. Moreover, the effect of variable thickness on the critical buckling load is also examined.

Keywords: Buckling; Crack; Plate; Peridynamics

\section{Introduction}

Ships and offshore structures are subjected to harsh marine environment which can cause several damage scenarios including fracture and corrosion. Buckling analysis of cracked plates is an important area for the design and analysis of hull girder strength of ship hulls and buckling column analysis of offshore oil and gas platforms and wind turbine structures. Cracked structures can demonstrate different buckling behaviour in terms of critical buckling loads and mode shapes with respect to their intact form. Therefore, investigation of buckling behaviour of cracked structures can provide invaluable information for the durability of the ships and offshore structures.

There are numerous studies in the literature focusing on buckling analysis of cracked plates [1,2]. Amongst these Khedmati et al. [3] studied how the buckling load varies with the length, orientation and location of the crack. This paper shows that the plate characteristic is completely different depending on where the crack is located, i.e. at the centre, edge of the plate or elsewhere. Nerantzaki and Katsikadelis [4] used the analogue equation method (AEM) to determine the buckling coefficient of plates with variable thickness. There are also studies on buckling analysis using the phase-field method. Amongst these Minh et. al. [5] studied the cracked plate considering various factors and Doan et. al. [6] studied the cracked rectangular plate with variable thickness. 
In addition, Zeng et. al. [7] studied side crack based on classical thin plate theory using the popular Ritz method. Kumar and Paik [8] used hierarchical trigonometric functions to estimate the buckling loads of cracked plates with various types of cracks and boundary conditions.

In this study, an alternative computational method, peridynamics [9-20], is utilised to perform buckling analysis of cracked plates. Peridynamics (PD) was introduced by Silling [21] to overcome the limitations of Classical Continuum Mechanics (CCM). Equations of motion of PD theory are in integro-differential equation form and they do not contain spatial derivatives which allow analysing discontinuities such as cracks without applying any special treatment to obtain the solution. A combination of standard peridynamic formulation to capture the in-plane deformation and Mindlin plate peridynamic formulation developed by Diyaroglu et al. [22] to represent bending deformation was used to formulate the problem. Numerical implementation was done using commercial finite element software, ANSYS, by following the approach described in Macek and Silling [23] and Yang et. al. [24]. Such an approach provides a straightforward way to determine the critical buckling loads and buckling mode shapes by using the buckling analysis algorithms already implemented in ANSYS software.

\section{Peridynamic theory}

\subsection{Basic theory}

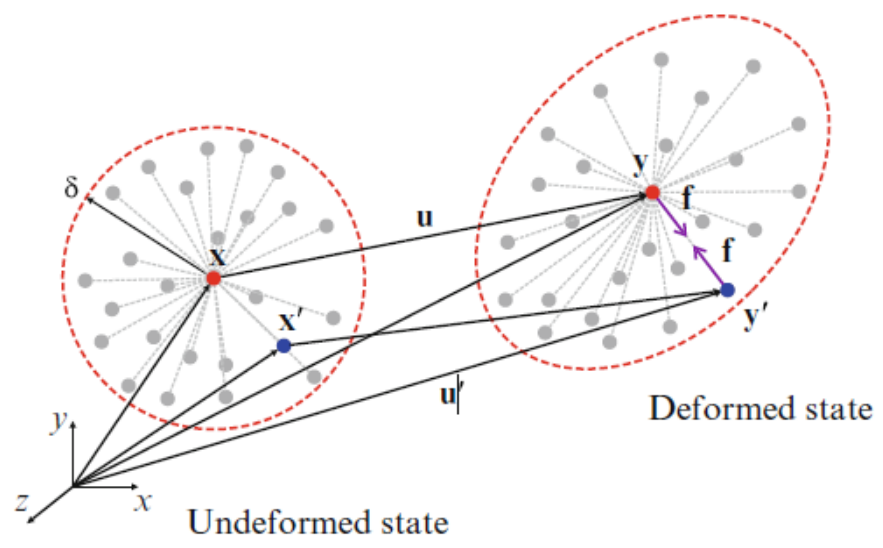

Figure 1. Peridynamic forces between materials points and the horizon concept [25].

To analyse the problems in structural mechanics, Cauchy's classical continuum mechanics (CCM) formulation has been widely used. However, equation of motion in $\mathrm{CCM}$ encounters difficulties if the displacement field is not continuous especially along crack boundaries. Therefore, Silling [21] introduced an alternative continuum 
mechanics formulation named as peridynamics to overcome the difficulties of CCM since peridynamic equation of motion is in the form of an integro-differential equation and does not contain any spatial derivatives which allow us to analyse problems with discontinuities. As other continuum mechanics formulations, a structure consists of infinitely small volumes called material points in PD theory. PD theory is a non-local continuum mechanics formulation. Therefore, material points can interact with each other in a non-local manner as long as they are located within a domain of influence called horizon, $\delta$. The material points which are inside the horizon of a particular material point are called family members as shown in Fig. 1.

\subsection{Equation of motion}

There are currently three main types of peridynamic formulations available in the literature depending on the interaction forces between material points. If the interaction forces between two materials points are in any direction and magnitude, this type of formulation is named as non-ordinary state-based peridynamics. If it is assumed that the interaction forces between two materials points are along the interaction (bond) direction but have different magnitudes, then this formulation is named as ordinarystate based peridynamics. Moreover, if the interaction forces between two material points are equal and opposite along the interaction direction, then this formulation corresponds to bond-based peridynamics formulation. The equation of motion of bondbased peridynamics can be written as

$$
\rho \ddot{\mathbf{u}}(\mathbf{x}, t)=\int_{H_{\mathbf{x}}} \mathbf{f}\left(\mathbf{u}\left(\mathbf{x}^{\prime}, t\right)-\mathbf{u}(\mathbf{x}, t), \mathbf{x}^{\prime}-\mathbf{x}\right) d V^{\prime}+\mathbf{b}(\mathbf{x}, t)
$$

where $\rho$ is the mass density, $H_{\mathbf{x}}$ represents the horizon of the material point $\mathbf{x}, \mathbf{u}$ and $\mathbf{x}$ are displacement and position vectors, respectively, and $\mathbf{b}$ represents the body force density exerting on the material point $\mathbf{x}$. Moreover, $\mathbf{f}$ is the peridynamic interaction force between two material points and it can be expressed as

$$
\mathbf{f}\left(\mathbf{u}^{\prime}-\mathbf{u}, \mathbf{x}^{\prime}-\mathbf{x}\right)=c s \frac{\mathbf{y}^{\prime}-\mathbf{y}}{\left|\mathbf{y}^{\prime}-\mathbf{y}\right|}
$$

with the stretch of the bond, $s$, is defined as

$$
s=\frac{\left|\mathbf{y}^{\prime}-\mathbf{y}\right|-\left|\mathbf{x}^{\prime}-\mathbf{x}\right|}{\left|\mathbf{x}^{\prime}-\mathbf{x}\right|}=\frac{|\xi+\boldsymbol{\eta}|-|\xi|}{|\xi|}
$$

where $\xi=\mathbf{x}^{\prime}-\mathbf{x}$ is the relative position vector between material points in the original configuration and $\boldsymbol{\eta}=\mathbf{u}^{\prime}-\mathbf{u}$ is the relative displacement vector between material points. 
Moreover, $\mathbf{y}$ is the relative position vector in the deformed configuration, i.e. $\mathbf{y}=\mathbf{x}+\mathbf{u}$. The bond constant $c$ is the material parameter in peridynamics and can be related to material constants of CCM as [26]

$$
c=\frac{18 \kappa}{\pi \delta^{4}} \quad(\text { for } 3-\mathrm{D})
$$

in which $\kappa$ is the bulk modulus and $\delta$ is the radius of the horizon.

It is usually not possible to obtain an analytical solution for the PD equation of motion given in Eq. (1). Therefore, numerical techniques such as meshless approach are widely utilised. Therefore, the peridynamic equation of motion of a material point $k$ can be expressed in discretised form as

$$
\rho_{(k)} \ddot{\mathbf{u}}_{(k)}=\sum_{j=1}^{N} \mathbf{f}\left(\mathbf{u}_{(j)}-\mathbf{u}_{(k)}, \mathbf{x}_{(j)}-\mathbf{x}_{(k)}\right) V_{(j)}+\mathbf{b}_{(k)}
$$

where $\rho_{(k)}$ is the mass density of the material point $k, N$ is the number of the family members within the horizon of the material point $k, \mathbf{u}_{(k)}$ is the displacement of the material point $k, V_{(j)}$ is the volume of the family member point $j$, and $\mathbf{b}_{(k)}$ is the body force density acting on the material point $k$.

\section{Peridynamic Mindlin plate formulation}

Structural idealizations such as beams, plates and shells can also be considered in peridynamics if the peridynamic equation of motion given in Eq. (1) is modified to take into account rotational degrees of freedom (DOF) in addition to translational degrees of freedom. One common formulation for structural idealisations is Mindlin plate formulation which is suitable for thick plates by taking into account transverse shear deformations. To derive the peridynamic equations for a Mindlin plate, out-of-plane deformation, $w$, and rotations, $\phi_{x}$ and $\phi_{y}$ should be considered as DOFs as shown in Fig. 2 .

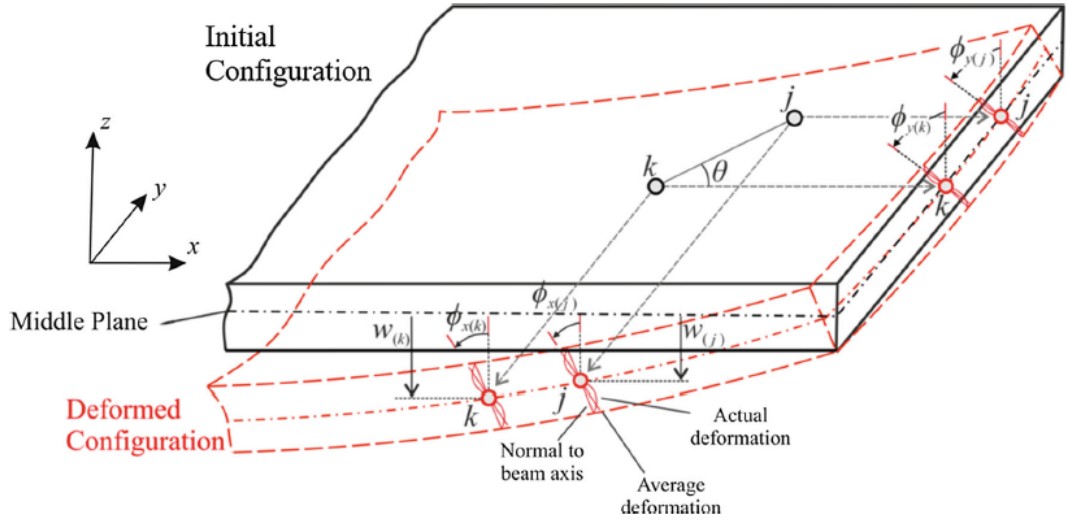

Figure 2. Initial and deformed configurations of peridynamic Mindlin plate formulation [22] 
As presented in Diyaroglu et. al. [22] and Yang et. al. [24], the three peridynamic equations of motion corresponding to each DOF for the material point $k$ can be written as

$$
\begin{gathered}
\rho V_{(k)} \ddot{w}_{(k)}=\sum_{j=1}^{N} \frac{c_{s}}{h} \varphi_{(k)(j)} V_{(j)} V_{(k)}+\hat{b}_{(k)} h, \\
\rho V_{(k)} \frac{I}{A} \ddot{\phi}_{x(k)}=\sum_{j=1}^{N} \frac{c_{b}}{h} \kappa_{(k)(j)} V_{(j)} V_{(k)}+\frac{1}{2} \sum_{j=1}^{N} \frac{c_{s}}{h} \varphi_{(k)(j)} \xi_{(j)(k)} \cos \theta V_{(j)} V_{(k)}+\tilde{b}_{x(k)} V_{(k)},(7)
\end{gathered}
$$

and

$$
\rho V_{(k)} \frac{I}{A} \ddot{\phi}_{y(k)}=\sum_{j=1}^{N} \frac{c_{b}}{h} \kappa_{(k)(j)} V_{(j)} V_{(k)}+\frac{1}{2} \sum_{j=1}^{N} \frac{c_{s}}{h} \varphi_{(k)(j)} \xi_{(j)(k)} \sin \theta V_{(j)} V_{(k)}+\tilde{b}_{y(k)} V_{(k)}
$$

where $h$ is the plate thickness. The shear angle and curvature arising from the interaction between material points $k$ and $j$ can be described as

$$
\begin{gathered}
\varphi_{(k)(j)}=\left(\frac{w_{(j)}-w_{(k)}}{\xi_{(k)(j)}}-\frac{\phi_{(j)}+\phi_{(k)}}{2}\right) \\
\kappa_{(k)(j)}=\frac{\phi_{(j)}-\phi_{(k)}}{\xi_{(k)(j)}}
\end{gathered}
$$

Peridynamic parameters $C_{s}$ and $c_{b}$ can be expressed in terms of elastic modulus, $E$ as

$$
c_{s}=\frac{9 E}{4 \pi \delta^{3}} k_{s}^{2}
$$

and

$$
c_{b}=\frac{3 h^{2} E}{4 \pi \delta^{3}}
$$

where $k_{s}$ represents the shear correction factor and the value of $\pi^{2} / 12$ is used for most plates [27].

\section{Implementation of peridynamic Mindlin plate formulation in ANSYS}

In this study, the numerical implementation of peridynamic equations was done by using the commercial finite element software, ANSYS and following the approach presented in Macek and Silling [23] and Yang et al. [24]. Although classical finite 
element method is based on CCM and peridynamics is a non-local continuum mechanics formulation, it is possible to implement peridynamic formulation in a commercial finite element software by representing peridynamic interactions with traditional finite elements and calibrating parameters of finite element analysis with parameters of peridynamic analysis.

Each peridynamic interaction in peridynamic Mindlin plate formulation presented in the previous section can be represented by using BEAM4 elements since this element has both translational and rotational DOFs and is a combination of link element and Timoshenko beam element. Based on Eqs. (6-8), peridynamic bond forces and moments between material points $k$ and $j$ can be expressed as

$$
\begin{aligned}
& \hat{f}_{(k)(j)}=\frac{C_{s}}{h} V_{(j)} V_{(k)} \varphi_{(k)(j)} \\
& \tilde{f}_{(k)(j)}=\frac{c_{b}}{h} V_{(j)} V_{(k)} \kappa_{(k)(j)}
\end{aligned}
$$

According to Classical Continuum Mechanics, the force and bending moment of a Timoshenko beam can be described as

$$
\begin{aligned}
& \hat{f}_{(k)(j)}=k_{s} A G_{(k)(j)} \varphi_{(k)(j)} \\
& \tilde{f}_{(k)(j)}=E_{(k)(j)} I_{y} \kappa_{(k)(j)}
\end{aligned}
$$

where $G_{(k)(j)}$ and $E_{(k)(j)}$ represent peridynamic shear modulus and Young's modulus of the bond between material points $k$ and $j$. $k_{s}, A$ and $I_{y}$ represent shear correction factor, cross-sectional area and moment of inertia of the beam, respectively. Note that these three parameters, i.e. $k_{s}, A$ and $I_{y}$, are geometrical properties that are calculated based on the distance between material points and plate thickness. Therefore, these values cannot be used as calibration parameters. On the other hand, $G_{(k)(j)}$ and $E_{(k)(j)}$ can serve as calibration parameters. By equating peridynamic and CCM forces and moments given in Eqs. $(13,14)$ and $(15,16)$, respectively, calibrated shear modulus and Young's modulus values to be used in finite element analysis can be obtained as

$$
G_{(k)(j)}=\frac{C_{s}}{k_{s} A h} V_{(j)} V_{(k)}
$$

and

$$
E_{(k)(j)}=\frac{c_{b}}{I_{y} h} V_{(j)} V_{(k)}
$$


BEAM4 elements can also represent in-plane deformations in addition to bending deformations which are important for the pre-buckling process. As explained in Macek and Silling [23], peridynamic forces for each interaction can be expressed as

$$
f_{(k)(j)}=c_{i} V_{(j)} V_{(k)} S_{(k)(j)}
$$

Corresponding force definition for BEAM4 element according to Classical Continuum Mechanics can be written as

$$
f_{(k)(j)}=E_{(k)(j)} A s_{(k)(j)}
$$

Once we equate Eqs. (19) and (20), we can obtain calibrated Young's modulus value as

$$
E_{(k)(j)}=\frac{c_{i} V_{(j)} V_{(k)}}{A}
$$

with

$$
c_{i}=\frac{9 E}{\pi h \delta^{3}}
$$

Note that calibrated Young's modulus values given in Eq. (18) for bending deformations and given in Eq. (22) for in-plane deformations are identical. Finally, critical buckling load is obtained by utilizing ANSYS Eigenvalue Buckling Analysis feature.

\section{Buckling analysis of cracked plates}

In this section, the buckling analysis of cracked plates is performed by using the peridynamic model implemented in ANSYS. ANSYS BEAM4 element is utilized to represent each bond between material points. Various crack configurations are considered to investigate the effect of crack length, crack orientation and plate thickness. Peridynamic results are compared with experimental results provided by Seifi et al. [28]. 


\subsection{Buckling analysis of a plate with and without a central crack}

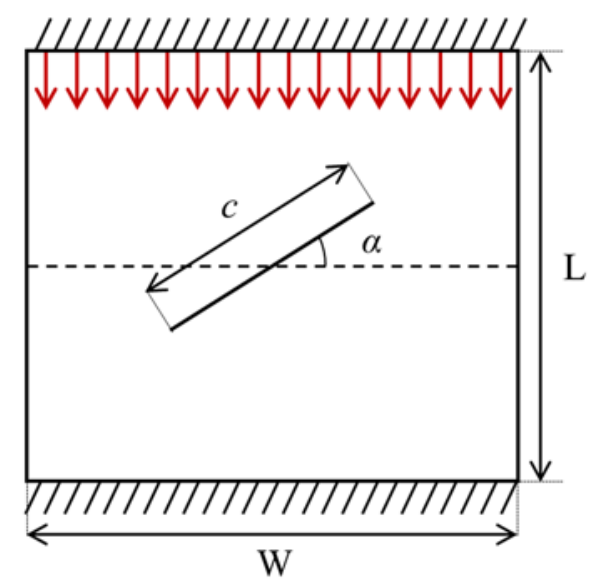

Figure 3. The geometry of a clamped-free-clamped-free plate with a crack

The plate illustrated in Fig. 3 is subjected to a clamped-free-clamped-free condition (CFCF) with thickness $h$, crack length $c$ and crack angle $\alpha$. The in-plane dimensions of the plate are $240 \times 240 \mathrm{~mm}^{2}$. The Young's modulus is $70 \mathrm{GPa}$ and Poisson's ratio is 0.33 . Various configurations are considered by changing plate thickness as $8 \mathrm{~mm}, 10$ $\mathrm{mm}$ and $12 \mathrm{~mm}$, crack angles as $0^{\circ}, 30^{\circ}$ and $60^{\circ}$ and crack length ratios $(c / W)$ as 0.1 , 0.3 and 0.5 . The two opposite sides of the plate are clamped and the other sides are free. Clamped-free-clamped-free condition (CFCF) is enforced by creating a fictitious region outside of the actual problem domain as shown in Fig. 4. The compressive loading is applied as body load corresponding to a unit load. 


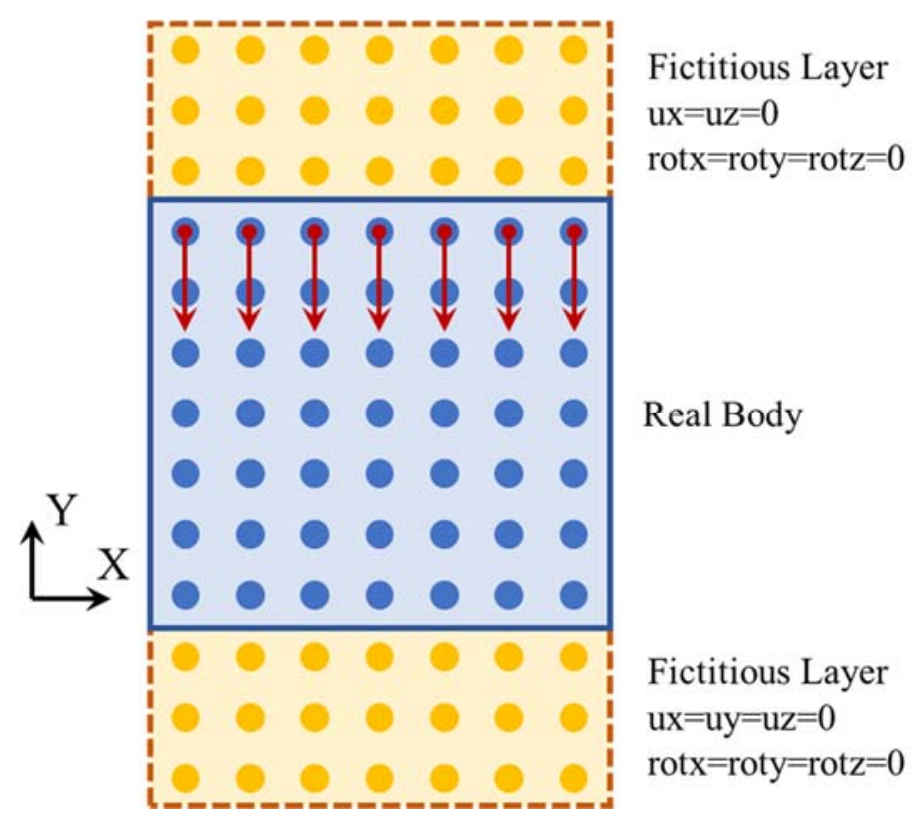

Figure 4. The boundary conditions of CFCF plate based on peridynamics

Table 1. Validation of peridynamic critical buckling load of the intact plate using

FEM

\begin{tabular}{llll}
\hline \hline $\begin{array}{l}\text { Thickness } \\
{[\mathrm{mm}]}\end{array}$ & $\begin{array}{l}\text { FEM } \\
\text { buckling load } \\
{[\mathrm{N}]}\end{array}$ & $\begin{array}{l}\text { Peridynamic } \\
\text { buckling load } \\
{[\mathrm{N}]}\end{array}$ & \% Diff \\
\hline 8 & 533.14 & 547.55 & 2.70 \\
10 & 1033.2 & 1053.0 & 1.92 \\
12 & 1768.9 & 1792.0 & 1.31 \\
\hline \hline
\end{tabular}

The effect of plate thickness is investigated first. Before analysing the cracked plate, the results of a plate without a crack (intact plate) using peridynamics and FEM are compared to verify whether the peridynamic results are reliable or not for various thickness configurations. The FEM results are obtained by using shell element in ANSYS and these results are summarized in Table 1. The differences between the two approaches are small and within 3\%. So, it can be concluded that the current peridynamic approach can be used for buckling analysis of a plate with a crack.

Next, buckling analysis of a plate with a central crack is performed. The critical buckling loads of cracked plates are compared with experimental results of Seifi et al. [28]. The plate has a thickness of $12 \mathrm{~mm}$. The comparison between peridynamic and experimental results for different crack angles and crack length ratios are given in Table 2. As can be seen in this table, the critical buckling load increases with the crack angle. On the other hand, as the crack length increases the critical load decreases. Moreover, the longer the crack length, the higher the effect of the crack angle. The differences 
between experimental and peridynamic results are within $8 \%$ which confirms the capability of the current approach for the buckling analysis of cracked plates.

Table 2. Comparison of experimental results for the critical buckling load of the plate with a central crack.

\begin{tabular}{lllll}
\hline \hline $\begin{array}{l}\text { Crack length } \\
\text { ratio } \\
(c / W)\end{array}$ & $\begin{array}{l}\text { Crack angle } \\
(\alpha)\end{array}$ & $\begin{array}{l}\text { Ref. [28] } \\
\text { Experimental } \\
{[\mathrm{N}]}\end{array}$ & $\begin{array}{l}\text { Peridynamics } \\
{[\mathrm{N}]}\end{array}$ & \% Diff \\
\hline 0.1 & $0^{\circ}$ & 1627 & 1746.4 & 7.34 \\
& $30^{\circ}$ & 1651 & 1762.1 & 6.73 \\
& $60^{\circ}$ & 1674 & 1777.1 & 6.16 \\
\hline 0.3 & $0^{\circ}$ & 1531 & 1562.6 & 2.06 \\
& $30^{\circ}$ & 1551 & 1631.7 & 5.20 \\
& $60^{\circ}$ & 1660 & 1729.4 & 4.18 \\
\hline 0.5 & $0^{\circ}$ & 1317 & 1311.7 & 0.40 \\
& $30^{\circ}$ & 1396 & 1471.6 & 5.42 \\
& $60^{\circ}$ & 1636 & 1683.5 & 2.90 \\
\hline
\end{tabular}

For other plate thicknesses, crack angles and crack length ratios, the results are given in Table 3 and also presented in graphs in Figs. 5 and 6. To see the effect of each parameter, the non-dimensional critical buckling load (NCBL) $k_{M}$ definition is used as

$$
k_{M}=\frac{N_{x} W^{2}}{\pi^{2} D}
$$

with

$$
D=\frac{E h^{3}}{12\left(1-v^{2}\right)}
$$

where $D$ is flexural rigidity of the plate. According to Figs. 5 and 6, the NCBL decreases as the thickness increases. It is evident that if the thickness increases, for a plate with same length and width, the plate's stiffness will increase. Note that NCBL is calculated by dividing the critical buckling load by stiffness. Therefore, as thickness increases, stiffness increases and higher critical buckling load and lower NCBL should be expected. Furthermore, regardless of the length of the crack, it can be seen that the thickness has similar effect on NCBL. This can be seen from the similar gradient of all NCBL-thickness graphs. In addition, while the initial crack angle increases from $0^{\circ}$ to 
$90^{\circ}$, the influence of crack length on NCBL declines. When the plates have same thickness, as the crack angle increases, the difference in value of NCBL depending on the crack length reduces gradually.

Table 3. Peridynamic results for critical buckling load of the plate with a central crack.

\begin{tabular}{|c|c|c|c|}
\hline $\begin{array}{l}\text { Thickness } \\
{[\mathrm{mm}]}\end{array}$ & $\begin{array}{l}\text { Crack length } \\
\text { ratio } \\
(c / W)\end{array}$ & $\begin{array}{l}\text { Crack angle } \\
(\alpha)\end{array}$ & $\begin{array}{l}\text { Peridynamics } \\
{[\mathrm{N}]}\end{array}$ \\
\hline \multirow[t]{8}{*}{8} & \multirow[t]{4}{*}{0.1} & $0^{\circ}$ & 536.33 \\
\hline & & $30^{\circ}$ & 539.04 \\
\hline & & $60^{\circ}$ & 543.37 \\
\hline & & $90^{\circ}$ & 545.86 \\
\hline & \multirow[t]{4}{*}{0.5} & $0^{\circ}$ & 404.17 \\
\hline & & $30^{\circ}$ & 454.09 \\
\hline & & $60^{\circ}$ & 517.29 \\
\hline & & $90^{\circ}$ & 536.97 \\
\hline \multirow[t]{8}{*}{10} & \multirow[t]{4}{*}{0.1} & $0^{\circ}$ & 1028.3 \\
\hline & & $30^{\circ}$ & 1036.0 \\
\hline & & $60^{\circ}$ & 1044.6 \\
\hline & & $90^{\circ}$ & 1049.7 \\
\hline & \multirow[t]{4}{*}{0.5} & $0^{\circ}$ & 772.81 \\
\hline & & $30^{\circ}$ & 868.77 \\
\hline & & $60^{\circ}$ & 991.91 \\
\hline & & $90^{\circ}$ & 1032.1 \\
\hline \multirow[t]{8}{*}{12} & \multirow[t]{4}{*}{0.1} & $0^{\circ}$ & 1746.4 \\
\hline & & $30^{\circ}$ & 1762.1 \\
\hline & & $60^{\circ}$ & 1777.1 \\
\hline & & $90^{\circ}$ & 1786.4 \\
\hline & \multirow[t]{4}{*}{0.5} & $0^{\circ}$ & 1311.7 \\
\hline & & $30^{\circ}$ & 1471.6 \\
\hline & & $60^{\circ}$ & 1683.5 \\
\hline & & $90^{\circ}$ & 1755.7 \\
\hline
\end{tabular}




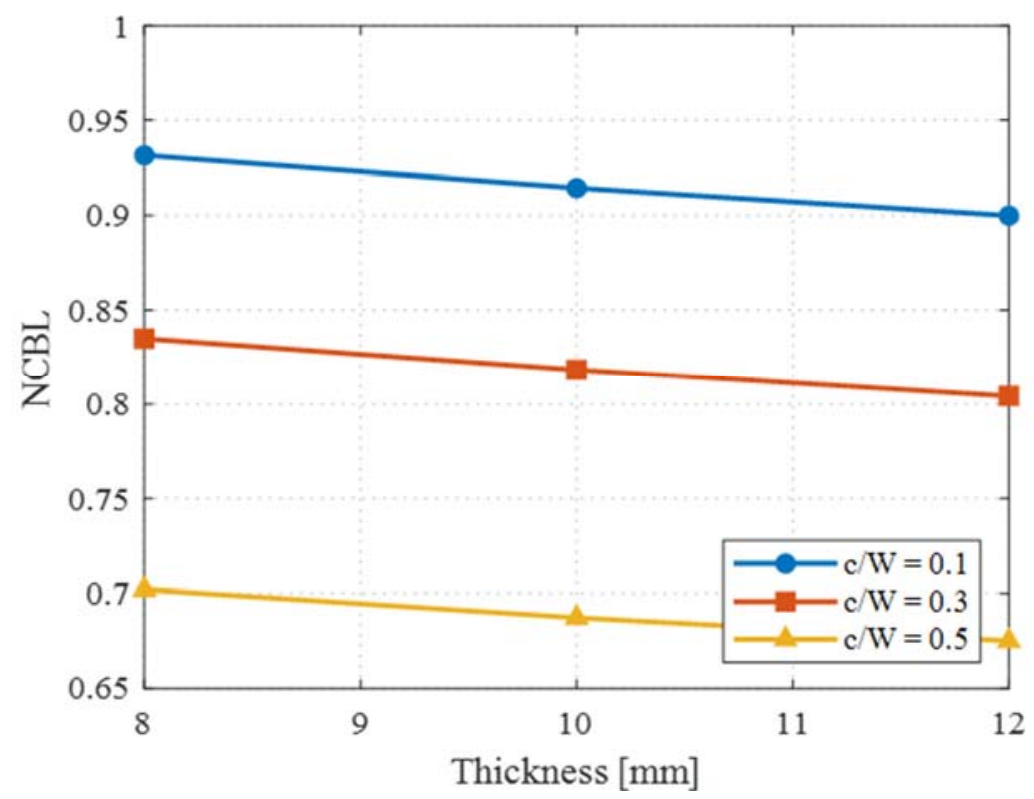

(a)

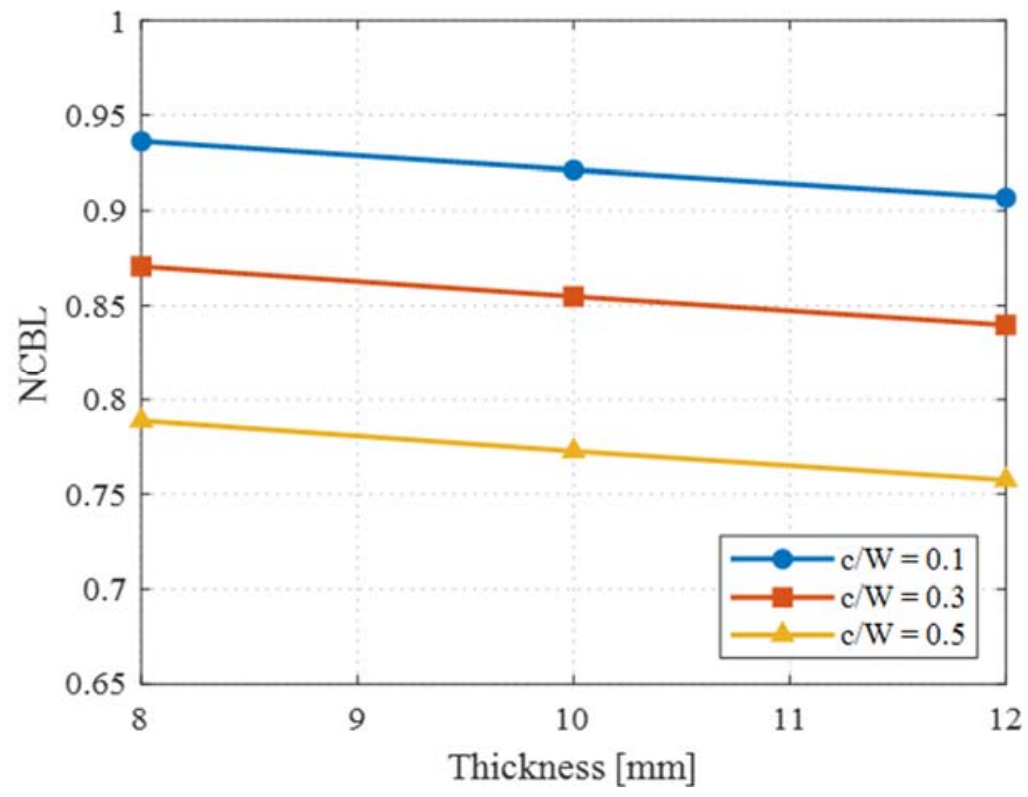

(b)

Figure 5. Effect of thickness on the non-dimensional critical buckling load of the plate with a central crack, ((a) $\alpha=0^{\circ}$, (b) $\left.\alpha=30^{\circ}\right)$ 


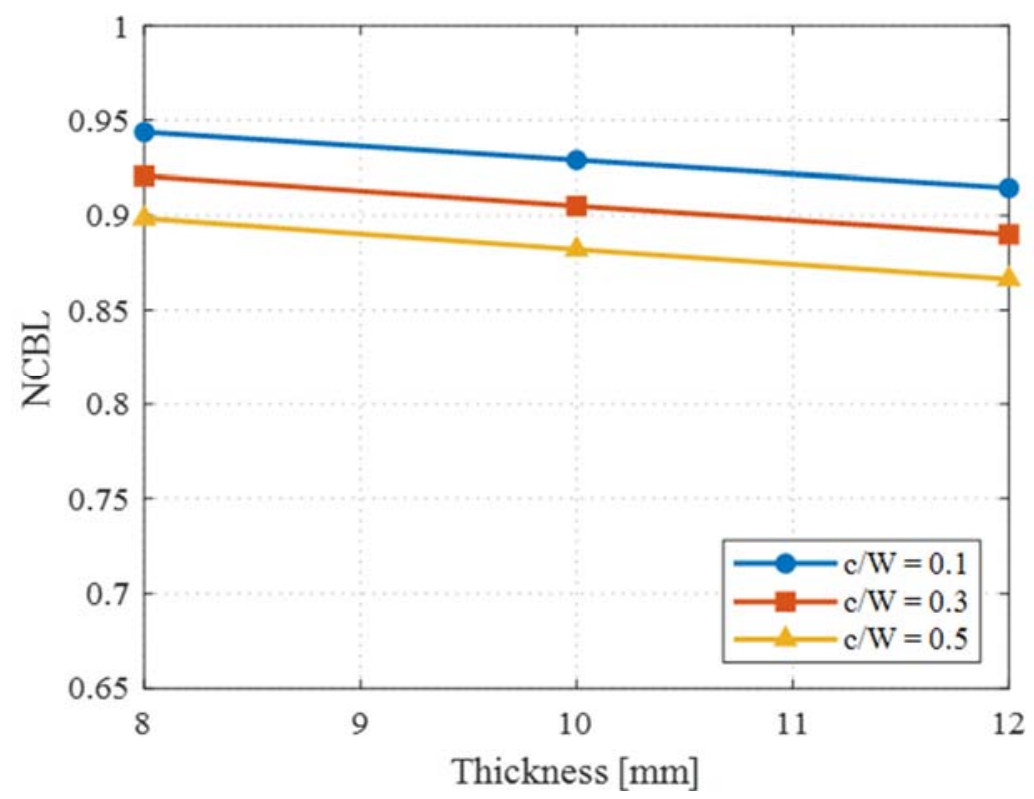

(a)

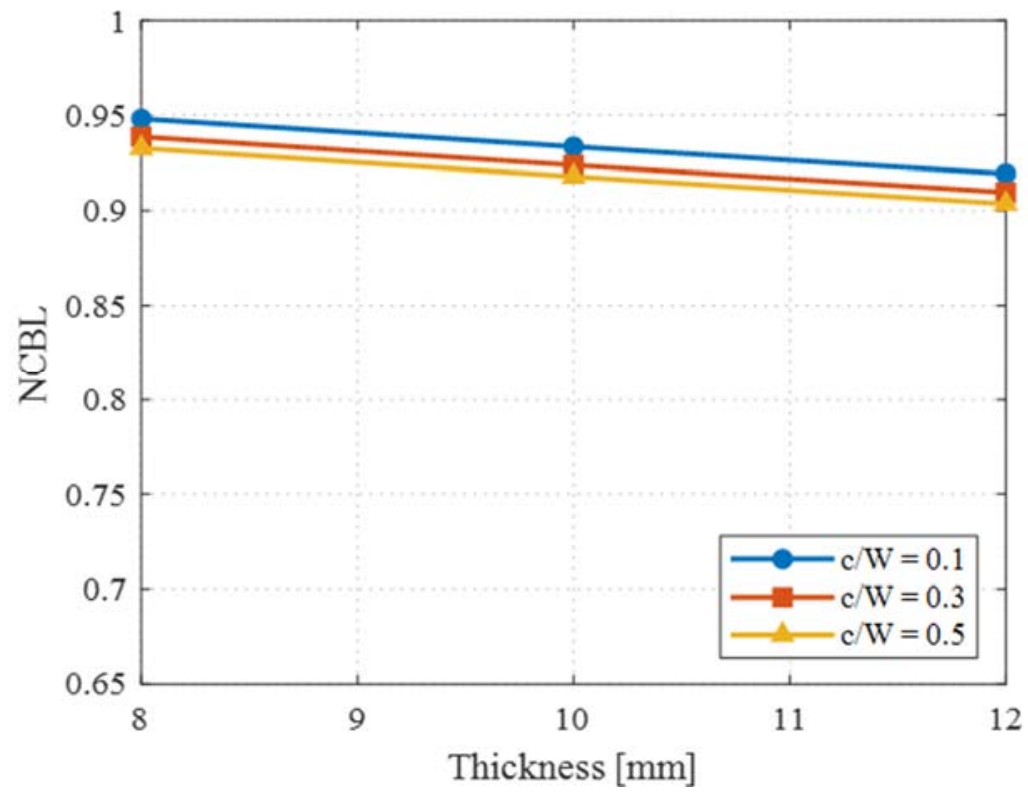

(b)

Figure 6. Effect of thickness on the non-dimensional critical buckling load of the plate with a central crack, ((a) $\alpha=60^{\circ}$, (b) $\alpha=90^{\circ}$ ) 


\subsection{Buckling analysis of a plate with a side-edge crack}

In this section, a similar case is considered by modifying the location of the crack from the center of the plate to the side-edge of the plate as shown in Fig. 7.

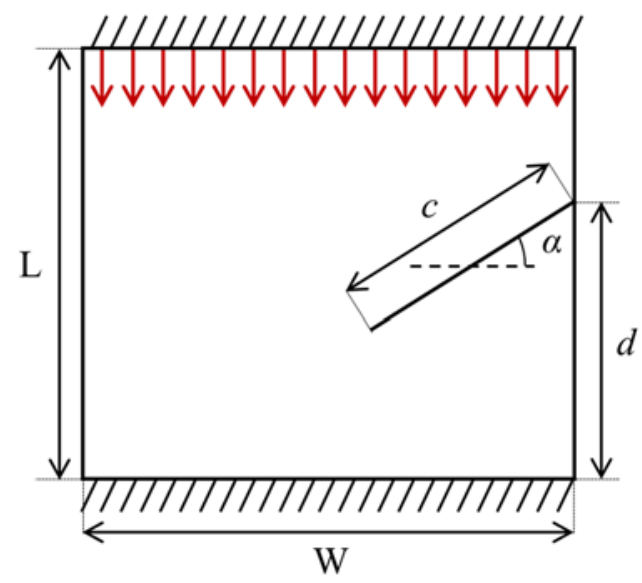

Figure 7. The geometry of a clamped-free-clamped-free plate with a side-edge crack 


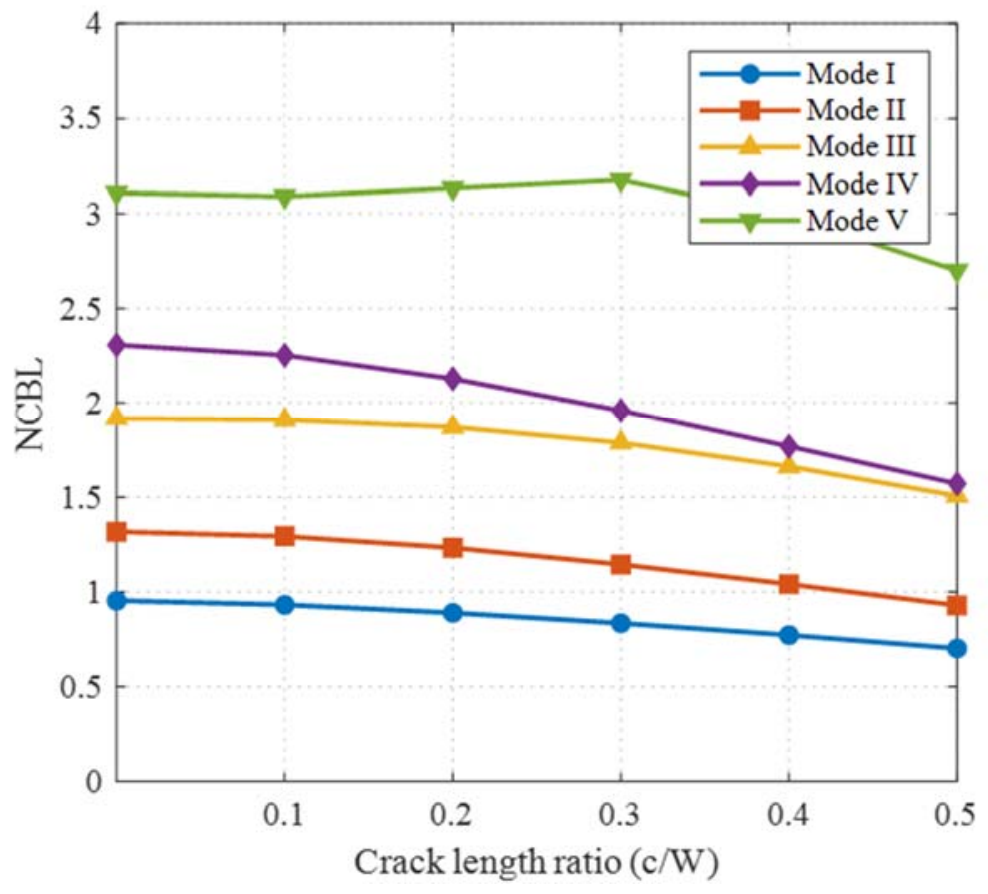

(a)

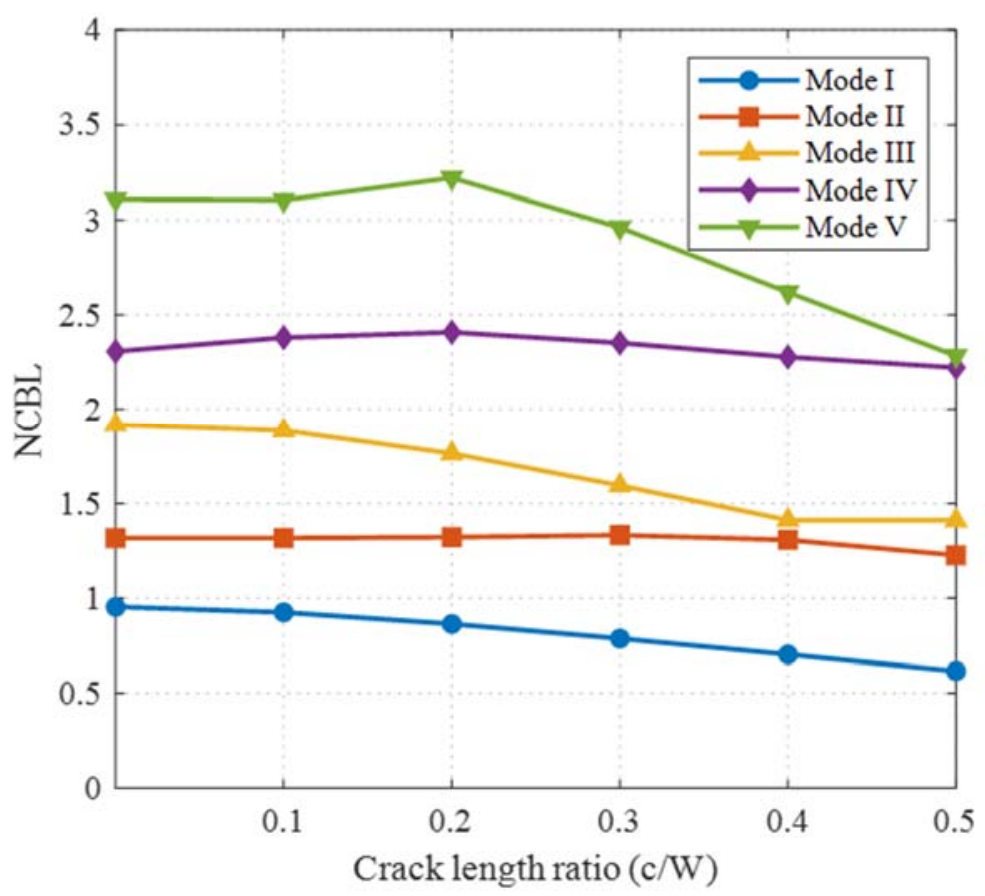

(b)

Figure 8. Variation of NCBL by crack length ((a) central crack, (b) side-edge crack) 
Table 4. Peridynamic results for critical buckling load of the plate with a side-edge crack

\begin{tabular}{|c|c|c|c|c|}
\hline $\begin{array}{l}\text { Thickness } \\
{[\mathrm{mm}]}\end{array}$ & $\begin{array}{l}\text { Crack angle } \\
(\alpha)\end{array}$ & $\begin{array}{l}\text { Crack length } \\
\text { ratio } \\
(c / W)\end{array}$ & $\begin{array}{l}\text { Crack } \\
\text { location ratio } \\
(d / L)\end{array}$ & $\begin{array}{l}\text { Peridynamics } \\
{[\mathrm{N}]}\end{array}$ \\
\hline \multirow[t]{12}{*}{8} & $0^{\circ}$ & 0.1 & 0.5 & 532.26 \\
\hline & & & 0.7 & 542.96 \\
\hline & & & 0.9 & 537.28 \\
\hline & & 0.5 & 0.5 & 355.16 \\
\hline & & & 0.7 & 378.17 \\
\hline & & & 0.9 & 398.41 \\
\hline & $60^{\circ}$ & 0.1 & 0.5 & 543.28 \\
\hline & & & 0.7 & 545.59 \\
\hline & & & 0.9 & 546.56 \\
\hline & & 0.5 & 0.5 & 487.68 \\
\hline & & & 0.7 & 486.02 \\
\hline & & & 0.9 & 470.39 \\
\hline \multirow[t]{12}{*}{12} & $0^{\circ}$ & 0.1 & 0.5 & 1733.99 \\
\hline & & & 0.7 & 1768.68 \\
\hline & & & 0.9 & 1750.75 \\
\hline & & 0.5 & 0.5 & 1154.36 \\
\hline & & & 0.7 & 1223.19 \\
\hline & & & 0.9 & 1291.62 \\
\hline & $60^{\circ}$ & 0.1 & 0.5 & 1771.34 \\
\hline & & & 0.7 & 1778.73 \\
\hline & & & 0.9 & 1781.68 \\
\hline & & 0.5 & 0.5 & 1587.05 \\
\hline & & & 0.7 & 1580.10 \\
\hline & & & 0.9 & 1533.00 \\
\hline
\end{tabular}




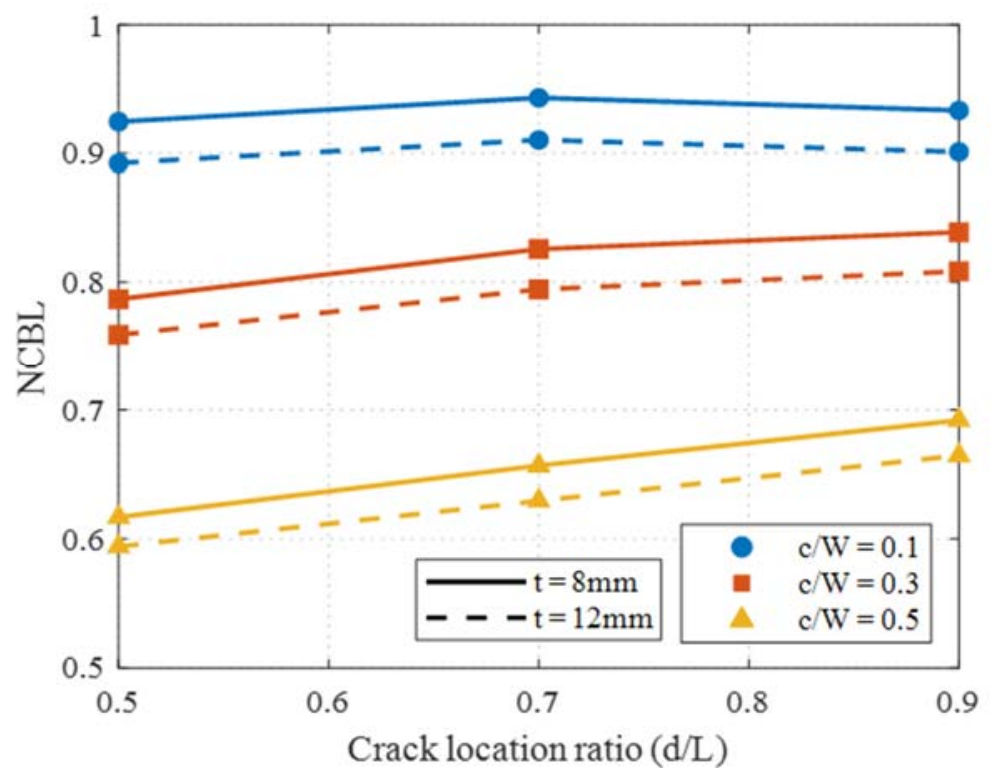

Figure 9. Effect of crack location on non-dimensional critical buckling load of the plate with a side-edge crack

Fig. 8 shows variation of NCBL for each buckling mode according to the crack length for the central and side-edge cracked plates. The thickness of each plate is $8 \mathrm{~mm}$ and the material properties are the same as the plate considered earlier. The critical buckling load decreases as the length of the crack increases. It is evident that the NCBL gradually reduces in the central crack case and the side-edge crack results are slightly different from the central crack results.

The critical buckling loads of side-edge cracked plate with different thickness, crack location, angle and size are summarized in Table 4 . When the crack angle is zero degree, the more the crack is placed in the middle of the plate $(d / L=0.5)$, the smaller the buckling load is required. In addition, when the crack is significantly large ( $c / W=$ $0.5)$, the critical buckling load gradually increases as the location of the crack moves away from the center of the plate. When the size of the crack is small $(c / W=0.1)$, there is slight change in buckling load with respect to its position.

As shown in Fig. 9, the effect of the crack position on the NCBL is investigated. The length and position of the crack changes for a plate having $8 \mathrm{~mm}$ or $12 \mathrm{~mm}$ thickness. As shown in the graph, NCBL increases as the crack is getting closer to the edge of the plate. Moreover, the slope shows that the shorter the length of the crack, the smaller the impact of the position. There is no significant difference between the two different thickness plate results. 


\subsection{Buckling analysis of a plate with a central crack and variable thickness}

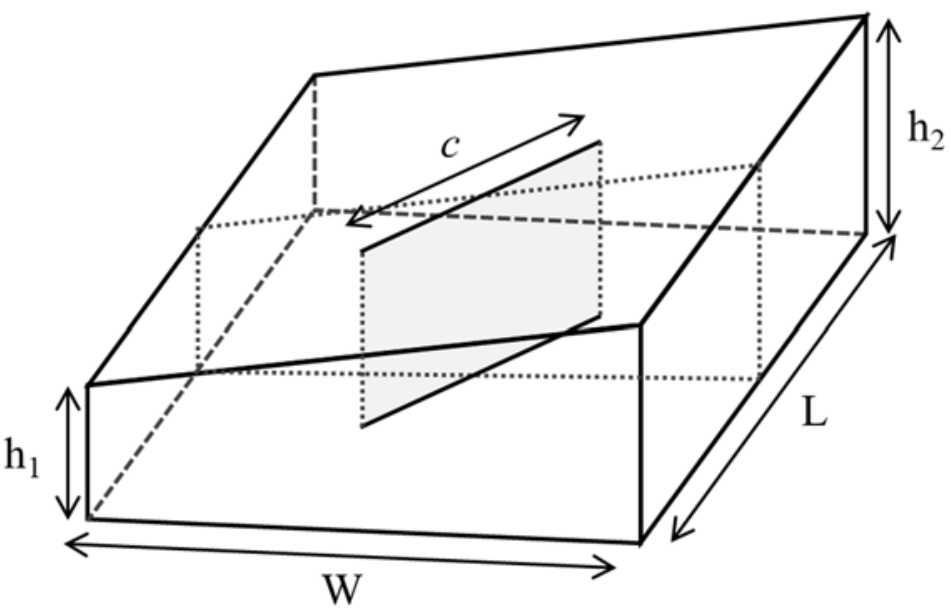

Figure 10. The geometry of a plate with a variable thickness along the length of the

plate

In this section, the buckling analysis is performed for a plate with a central crack and linearly increased thickness. The size of the plate is $240 \times 240 \mathrm{~mm}^{2}$. Loading and boundary conditions are the same as in Section 5.1. As shown in Fig. 10 the plate has a varying thickness along the direction of its width. The $h_{1}$ and $h_{2}$ parameters represent the smallest and longest thicknesses of the plate, respectively. The plate is investigated with different thickness ratios $\left(h_{2} / h_{1}\right)$ changing from 1.1 to $2.0 . h_{1}$ is specified as 6 mm. Other crack-related constants, such as crack length and angle, are considered the same as in the previous section. The material properties are also the same as in the previous section, which is Young's modulus is $70 \mathrm{GPa}$ and Poisson's ratio is 0.33 .

Table 5. Comparison of FEM and peridynamic critical buckling load of the intact plate with variable thickness

\begin{tabular}{llll}
\hline \hline $\begin{array}{l}\text { Thickness ratio } \\
\left(h_{2} / h_{1}\right)\end{array}$ & $\begin{array}{l}\text { FEM } \\
\text { buckling load } \\
{[\mathrm{N}]}\end{array}$ & $\begin{array}{l}\text { Peridynamic } \\
\text { buckling load } \\
{[\mathrm{N}]}\end{array}$ & \% Diff \\
\hline 1.1 & 260.41 & 271.48 & 4.25 \\
1.2 & 294.85 & 306.66 & 4.01 \\
1.5 & 404.02 & 417.68 & 3.38 \\
1.75 & 506.00 & 520.90 & 2.94 \\
2.0 & 621.06 & 636.95 & 2.56 \\
\hline \hline
\end{tabular}


Firstly, the peridynamic model results for an intact plate are compared with the FEM results for verification purposes. The shell element of ANSYS was used for FEM results. The results are summarized in Table 5. It can be seen that the differences between peridynamics and FEM results are smaller than 5\%. The critical buckling load increases as the thickness ratio is increases. This is because as the thickness increases the plate resists more to bending. This means that greater load is needed for buckling, which increases the critical buckling load.

The critical buckling loads of cracked plate are given in Table 6. Similar to the intact plate case, the buckling load increases as the ratio of thickness increases. The higher the thickness ratio, the more significant decrease in buckling load is observed as the size of the crack increases. The change in crack angle with the same thickness ratio and length of the crack is not very influential compared to other factors.

According to Figs. 11 and 12, the values of NCBL show that the crack affects the stiffness of the plate. The thickness ratio has a significant effect, as with other factors, in buckling analysis. The value of NCBL decreases as the ratio of thickness increases. As with the previous results, the smaller angle of crack, the more significant impact of the length of the crack is observed. The gradient of all graphs is similar, indicating that the influence of the ratio of thickness is constant regardless of the crack length and angle. 
Table 6. Peridynamic results for critical buckling load of the plate with a central crack and variable thickness

\begin{tabular}{|c|c|c|c|}
\hline $\begin{array}{l}\text { Crack angle } \\
(\alpha)\end{array}$ & $\begin{array}{l}\text { Crack length } \\
\text { ratio } \\
(c / W) \\
\end{array}$ & $\begin{array}{l}\text { Thickness ratio } \\
\left(h_{2} / h_{1}\right)\end{array}$ & Peridynamics $[\mathrm{N}]$ \\
\hline \multirow[t]{8}{*}{$0^{\circ}$} & \multirow[t]{4}{*}{0.1} & 1.1 & 265.45 \\
\hline & & 1.2 & 299.82 \\
\hline & & 1.5 & 408.32 \\
\hline & & 2.0 & 622.63 \\
\hline & \multirow[t]{4}{*}{0.5} & 1.1 & 200.11 \\
\hline & & 1.2 & 224.61 \\
\hline & & 1.5 & 300.01 \\
\hline & & 2.0 & 448.36 \\
\hline \multirow[t]{8}{*}{$30^{\circ}$} & \multirow[t]{4}{*}{0.1} & 1.1 & 267.39 \\
\hline & & 1.2 & 302.05 \\
\hline & & 1.5 & 411.47 \\
\hline & & 2.0 & 627.54 \\
\hline & \multirow[t]{4}{*}{0.5} & 1.1 & 226.80 \\
\hline & & 1.2 & 254.36 \\
\hline & & 1.5 & 339.33 \\
\hline & & 2.0 & 506.74 \\
\hline \multirow[t]{8}{*}{$60^{\circ}$} & \multirow[t]{4}{*}{0.1} & 1.1 & 269.62 \\
\hline & & 1.2 & 304.60 \\
\hline & & 1.5 & 415.05 \\
\hline & & 2.0 & 633.03 \\
\hline & \multirow[t]{4}{*}{0.5} & 1.1 & 256.84 \\
\hline & & 1.2 & 288.73 \\
\hline & & 1.5 & 387.41 \\
\hline & & 2.0 & 579.96 \\
\hline
\end{tabular}




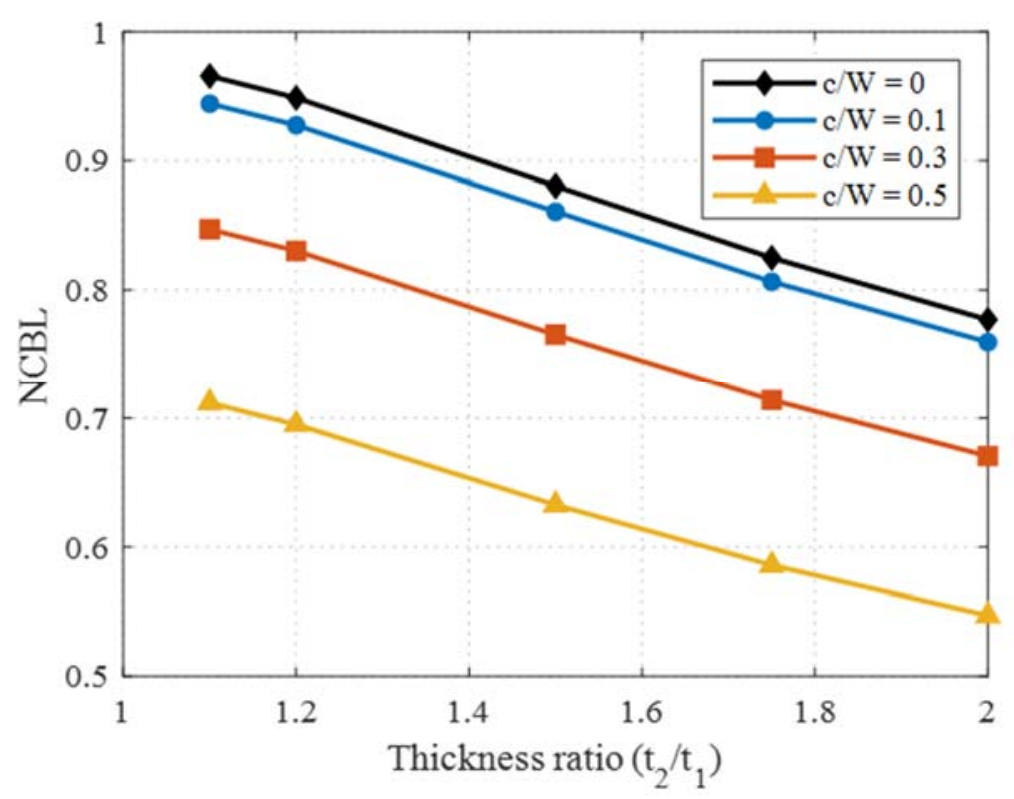

(a)

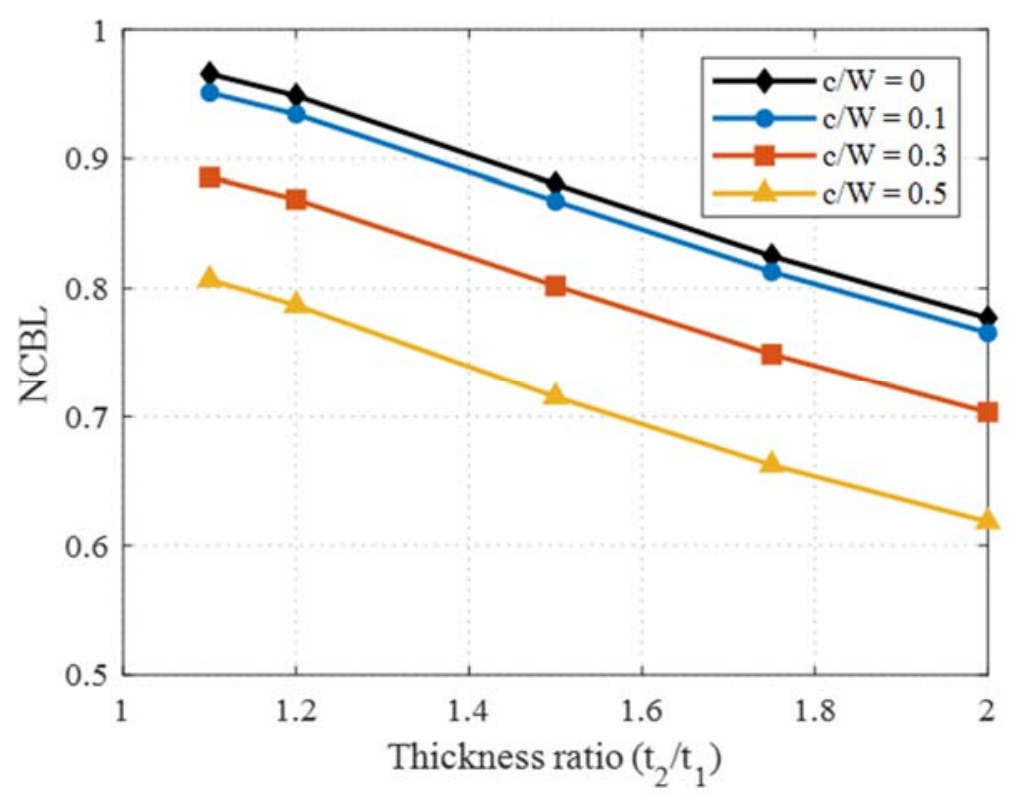

(b)

Figure 11. Effect of thickness ratio on the non-dimensional critical buckling load of the plate with a central crack and variable thickness, ((a) $\alpha=0^{\circ}$, (b) $\alpha=30^{\circ}$ ) 


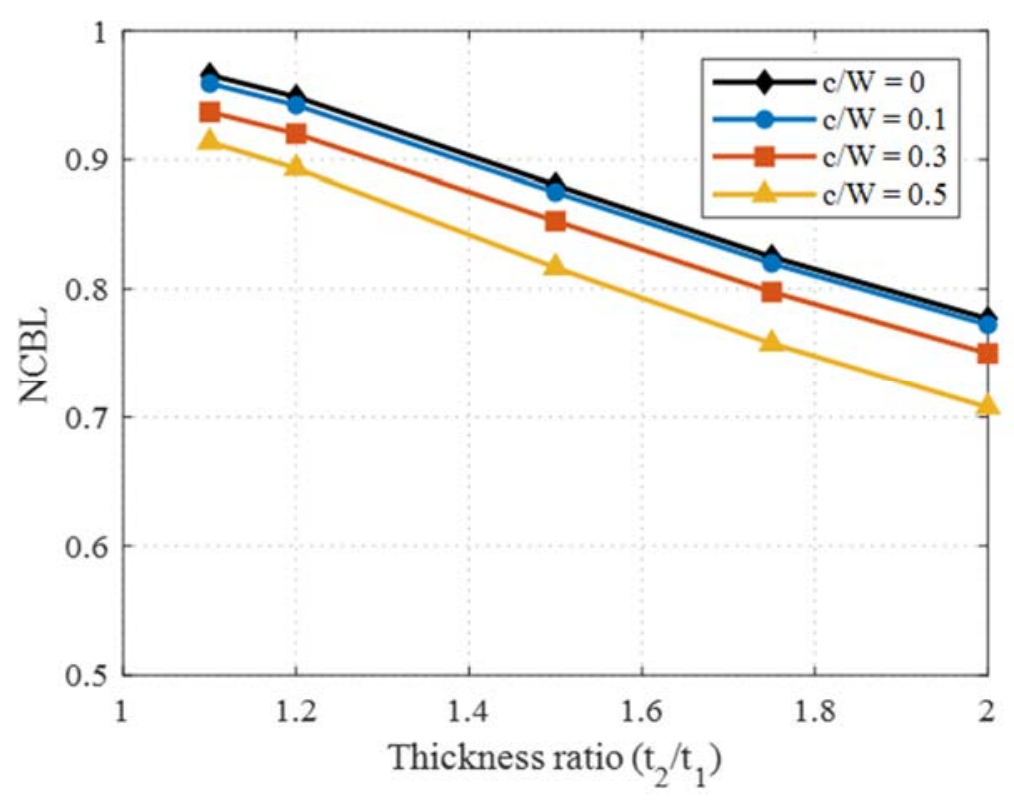

(a)

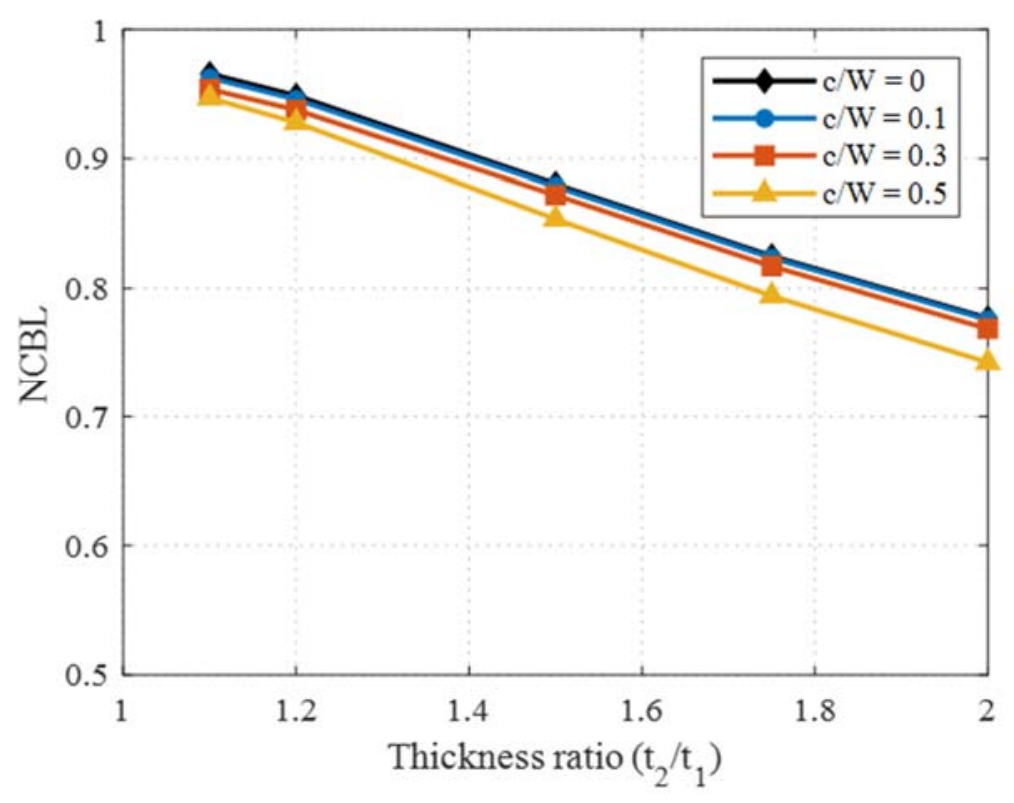

(b)

Figure 12. Effect of thickness ratio on the non-dimensional critical buckling load of the plate with a central crack and variable thickness, ((a) $\alpha=60^{\circ}$, (b) $\alpha=90^{\circ}$ ) 


\section{Conclusions}

In this study, buckling analysis of cracked plates was performed by using peridynamics. Peridynamic formulation was verified by considering a plate with and without a crack. Peridynamic results were compared against numerical and experimental results and a good agreement was obtained between different approaches. After verifying the formulation, it was utilised to investigate the effect of crack length, crack orientation and plate thickness on the critical buckling load values for a centrally and side-edge cracked plates with CFCF boundary conditions. Moreover, the effect of variable thickness on critical buckling load was also examined. For centrally cracked plate, the critical buckling load increases with the crack angle. On the other hand, as the crack length increases the critical load decreases. For the side-edge cracked plate, the shorter the length of the crack, the smaller the impact of the position of the crack was observed. For the centrally cracked plate with variable thickness, the thickness ratio has a significant effect, as with other factors, in buckling analysis and the influence of the ratio of thickness is constant regardless of the crack length and angle.

\section{Acknowledgements}

This research was funded and conducted under "the Competency Development Program for Industry Specialists"of the Korean Ministry of Trade, Industry and Energy (MOTIE), operated by Korean Institute for Advancement of Technology (KIAT). (No. N0001287, HRD program for Korea-UK Global Engineer Education Program for Offshore Plant).

\section{References}

[1] Markstrom, K. and Storakers, B., "Buckling of cracked members under tension," International Journal of Solids and Structures, vol. 16, pp. 217-229, 1980.

[2] Shaw, D. and Huang, Y., "Buckling behavior of a central cracked thin plate under tension,” Engineering Fracture Mechanics, vol. 35, no. 6, pp. 1019-1027, 1990.

[3] Khedmati, M.R., Edalat, P. and Javidruzi, M., "Sensitivity analysis of the elastic buckling of cracked plate elements under axial compression," Thin-Walled Structures, vol. 47, no. 5, pp. 522-536, 2009.

[4] Nerantzaki, M. and Katsikadelis, J., "Buckling of plates with variable thickness an analog equation solution," Engineering Analysis with Boundary Elements, vol. 18, no. 2, pp. 149-154, 1996.

[5] Minh, P.P., Van Do, T., Duc, D.H. and Duc, N.D., "The stability of cracked rectangular plate with variable thickness using phase field method," Thin-Walled Structures, vol. 129, pp. 157-165, 2018. 
[6] Doan, D.H., Van Do, T., Pham, P.M., Duc, N.D., “ Validation simulation for free vibration and buckling of cracked Mindlin plates using phase-field method," Mechanics of Advanced Materials and Structures, vol. 26(12), pp. 1018-1027, 2019.

[7] Zeng, H.C., Huang, C.S., Leissa, A.W. and Chang, M. J., "Vibrations and stability of a loaded side-cracked rectangular plate via the MLS-Ritz method," Thin-Walled Structures, vol. 106, pp. 459-470, 2016.

[8] Kumar, Y.V. and Paik, J.K., "Buckling analysis of cracked plates using hierarchical trigonometric functions," Thin-Walled Structures, vol. 42, no. 5, pp. 687-700, 2004.

[9] Javili, A., Morasata, R., Oterkus, E. and Oterkus, S., "Peridynamics review," Mathematics and Mechanics of Solids, vol. 24(11), pp. 3714-3739, 2019.

[10] De Meo, D., Zhu, N. and Oterkus, E., "Peridynamic modeling of granular fracture in polycrystalline materials," Journal of Engineering Materials and Technology, vol. 138(4), 2016.

[11] Oterkus, E. and Madenci, E., "Peridynamics for failure prediction in composites," In 53rd AIAA/ASME/ASCE/AHS/ASC Structures, Structural Dynamics and Materials Conference 20th AIAA/ASME/AHS Adaptive Structures Conference 14th AIAA (p. 1692), 2012.

[12] Wang, H., Oterkus, E. and Oterkus, S., "Predicting fracture evolution during lithiation process using peridynamics," Engineering Fracture Mechanics, vol. 192, pp.176-191, 2018.

[13] Gao, Y. and Oterkus, S., "Ordinary state-based peridynamic modelling for fully coupled thermoelastic problems," Continuum Mechanics and Thermodynamics, vol. 31(4), pp. 907-937, 2019.

[14] Imachi, M., Tanaka, S., Ozdemir, M., Bui, T.Q., Oterkus, S. and Oterkus, E., “ Dynamic crack arrest analysis by ordinary state-based peridynamics," International Journal of Fracture, vol. 221, pp.155-169, 2020.

[15] Yang, Z., Vazic, B., Diyaroglu, C., Oterkus, E. and Oterkus, S., "A Kirchhoff plate formulation in a state-based peridynamic framework," Mathematics and Mechanics of Solids, vol. 25(3), pp.727-738, 2020.

[16] Javili, A., McBride, A.T. and Steinmann, P. "Continuum-kinematics-inspired peridynamics. Mechanical problems," Journal of the Mechanics and Physics of Solids, vol. 131, pp.125-146, 2019.

[17] Ni, T., Zaccariotto, M., Zhu, Q.Z. and Galvanetto, U. "Static solution of crack propagation problems in Peridynamics," Computer Methods in Applied Mechanics and Engineering, vol. 346, pp.126-151, 2019. 
[18] Chowdhury, S.R., Roy, P., Roy, D. and Reddy, J.N. “A modified peridynamics correspondence principle: Removal of zero-energy deformation and other implications," Computer Methods in Applied Mechanics and Engineering, Vol. 346, pp.530-549, 2019.

[19] Liu, S., Fang, G., Liang, J., Fu, M. and Wang, B. “A new type of peridynamics: Element-based peridynamics," Computer Methods in Applied Mechanics and Engineering, vol. 366, p.113098, 2020.

[20] Gu, X., Zhang, Q., Madenci, E. and Xia, X. "Possible causes of numerical oscillations in non-ordinary state-based peridynamics and a bond-associated higherorder stabilized model," Computer Methods in Applied Mechanics and Engineering, vol. 357, p.112592, 2019.

[21] Silling, S.A. "Reformulation of elasticity theory for discontinuities and long-range forces," Journal of the Mechanics and Physics of Solids, vol. 48(1), pp.175-209, 2000.

[22] Diyaroglu C., Oterkus E., Oterkus S. and Madenci E. "Peridynamics for bending of beams and plates with transverse shear deformation," International Journal of Solids and Structures, vol. 69-70, pp. 152-168, 2015.

[23] R. W. Macek and S. A. Silling, "Peridynamics via finite element analysis," Finite Elements in Analysis and Design, vol. 43(15), pp. 1169-1178, 2007.

[24] Yang Z., Oterkus E., Nguyen C.T. and Oterkus S., "Implementation of peridynamic beam and plate formulations in finite element framework," Continuum Mechanics and Thermodynamics, Vol. 31(1), pp. 301-315, 2019.

[25] Madenci E., Oterkus E. Peridynamic Theory and Its Applications. New York, NY: Springer, 2014.

[26] Silling S.A., Askari E., "A meshfree method based on the peridynamic model of solid mechanics, Computers \& Structures, vol. 83(17-18), pp. 1526-1535, 2005.

[27] Stephen N., "Mindlin plate theory: best shear coefficient and higher spectra validity," Journal of Sound and Vibration, vol. 202(4), pp. 539-553, 1997.

[28] Seifi, R. and Khoda-Yari, N., "Experimental and numerical studies on buckling of cracked thin-plates under full and partial compression edge loading," Thin-Walled Structures, vol. 49(12), pp. 1504-1516, 2011. 